\title{
Influence of Immigrant Background onthe Outcome of Total Hip ArthroplastyBetter outcome in 280 Native Patients in Bosnia and Herzegovinian than in $\mathbf{4 4 9}$ Immigrants Living in Sweden
}

Ferid Krupic ( $\nabla$ ferid.krupic@gu.se)

Institute of Clinical Sciences, Dept. of Orthopaedics, Sahlgrenska Akademy at University of Gothenburg, Gothenburg, Sweden.

Slavko Manojlovic

School of Medicine, University of Banjaluka, Banjaluka, Bosnia and Herzegovina.

Svemir Custovic

Clinic for Orthopaedics and Traumatology, University Clinical Center Tuzla, Bosnia and Herzegovina

Mirsad Fazlic

Clinic for Orthopaedics and Traumatology, University Clinical Center Tuzla, Bosnia and Herzegovina

Sahmir Sadic

Clinic for Orthopaedics and Traumatology, University Clinical Center Tuzla, Bosnia and Herzegovina Johan Kärrholm

Institute of Clinical Sciences, Dept. of Orthopaedics, Sahlgrenska Akademy at University of Gothenburg, Gothenburg, Sweden.

\section{Research Article}

Keywords:

Posted Date: January 18th, 2022

DOI: https://doi.org/10.21203/rs.3.rs-1152752/v1

License: () (1) This work is licensed under a Creative Commons Attribution 4.0 International License. Read Full License 


\section{Abstract}

Background: Despite the overall success of THA, betwen 5-20\% report unsatisfactory results. Several factors may cause this variable outcome. One of them is ethnicity, which because of its potential social impact on living conditions may influence life quality. We investigated whether patients born and operated in their home country Bosnia and Herzegovina, report the same results as do patients living in Sweden, born in Europe outside the Nordic countries.

Methods: Data were prospectively collected from 280 patients planned to be operated with a THA in Bosnia and Herzegovina, and 449 immigrants born in Europe but outside the Nordic countries. Logistic and linear regression models including age, sex, diagnosis, type of fixation, surgical incision, marital status, and education level were analyzed. Outcomes were the 5 dimensions in EQ-5D, EQ-VAS, pain, VAS, and satisfaction VAS. Data collected before the operation and 1 year after were studied.

Results: Before the operation patients born and living in Bosnia and Herzegovina reported more problems with self-care and usual activities before and after adjustment for confounding. Patients living in Sweden reported higher EQ-VAS and more pain on VAS than did those born in Bosnia and Herzegovina, but the difference in EQ-VAS became statistically insignificant after adjustment for confounding. A higher share of patients living in Bosnia and Herzegovina reported more benefit 1 year after the operation in all dimension except from self-care as reflected in the basic chi-square test and the unadjusted and adjusted regression analyses. After adjustment for confounding this group of patients was also more satisfied, but there was no statistically significant difference in pain VAS and EQ-VAS when compared to the immigrant group living in Sweden.

Conclusion: Our findings that immigrant patients operated in Sweden despite a tendency to more symptoms before the operation have less benefit from a THA according to EQ5D 1 year after the operation cause concern. We do not know to what extent this situation can be improved by a more multidimensional caretaking of immigrant patients. Probably other factors not only involving the healthcare system play a role as do probably also methodological problems related to these types of studies.

\section{Background}

The goal of Total Hip Arthroplasty (THA) surgery is to improve mobility, function and quality of life and to reduce pain. Despite the overall success of THA, between $5-10 \%$ and in some studies up to $15-20 \%$ have been found to be dissatisfied after the surgery [1-3]. Various factors may cause this variable outcome. One of them is ethnicity, which because of its potential social impact on living conditions, will affect the quality of life. Several other factors have been found to at a varying extent influence patient satisfaction after THA such as age, gender, comorbidities, preoperative diagnosis, severity of arthropathy, patient expectations, preoperative pain at rest, lower preoperative quality of life, mental disorders and occurrence of postoperative complications [4-6]. Some studies have reported that there are differences in utilization due to race without relation to variations in access to health care, income, or insurance plan [7]. Other studies, on the other side, showed that ethnic disparities in THA surgery are caused by insufficient provision of preoperative information to some patient groups. Proper information may reduce preoperative anxiety, which may improve 
surgical outcomes, shorten hospital stay, and minimize any disruption of lifestyle [8-10]. Cultural and socioeconomic background, educational level, patient expectations, pain reporting and management of pain can be more or less related to ethnicity and race [11-14].

Sweden has received immigrants from many countries around the world for decades. During the last years this immigration has increased [15]. This increase has not been accompanied by an increasing research of how ethnic, socioeconomic, linguistic, cultural and to some extent religious issues may affect the outcome of the THA surgery. Only a few studies have compared the outcome of patients born abroad with patients born in Sweden [16, 14, 17-20]. Given the evidence of ethnical disparities in arthroplasty utilization and outcomes, there is a need to identify factors potentially associated with these disparities. We investigated whether patients born and operated in their home country Bosnia and Herzegovina, report the same results as do patients born in Europe outside the Nordic countries. Our hypothesis was that patients operated in their home country would report superior results one year after the operation because of a more familiar environment, absence of language problems, cultural alienation and for most of them refugee status.

\section{Patients And Methods}

This study was conducted at Sahlgrenska University Hospital and two University Hospitals in Bosnia and Herzegovina (Tuzla and Banjaluka). The data for the patients operated in Sweden was extracted from Swedish Joint Arthroplasty Register (SJAR). THAs from the SJAR with a complete preoperative and 1-year postoperative follow-up PROM protocol up to December 2008 were selected. This study used routinely collected data from the Swedish Joint Arthroplasty Register including basic demographic variables and patient-reported outcome measures. We defined an immigrant person as an individual born abroad with 2 parents who were also born abroad, indicating that this person probably not has Swedish as native language. We selected 449 immigrants living in Sweden from Europe outside the Nordic countries based on presence of a complete data set after cross-matching with Statistics, Sweden. Data from Statistics Sweden were used to obtain information about country of birth, educational level, and cohabitation.

Our plan was from the beginning to match patients born in Bosnia and Herzegovina and operated in their home country, against patients from the same community who live in Sweden and are operated in Sweden. This could not be done because Statistics Sweden only delivers detailed information about country of birth for some countries but not for all. European countries outside the Nordic ones are grouped together. Since our focus were on native patients from Bosnia and Herzegovina operated in their home country our reference group of immigrants living in Sweden could at best be selected from those born in European countries outside the Nordic ones.

During the year 2011, 96467 immigrants arrived in Sweden and among them 26776 (36\%) were born in Europe and outside the Nordic countries. 2173 came from Bosnia and Herzegovina (8.1\% of European immigrants living outside the Nordic countries). The data collection for patients born and living in Bosnia and Herzegovina and operated with THA in their home country was done in several steps. The first author of the study contacted an authorized interpreter who translated the EQ5D form into the Bosnian language. Thereafter, arthroplasty surgeons in Banjaluka and Tuzla were contacted to organize the data collecting process, which was performed between January 2016 to December 2018. PROMs were collected 
preoperatively and 1 year after the insertion of a THA and was supervised by a nurse at each hospital who transferred each form to database. Preoperatively, patients filled in the forms within 4 weeks before the operation.

\section{Sources of data}

In Tuzla and Banjaluka, a nurse contacted the patients about 1 month before surgery, who informed them about the project and asked about participation. The patients who wanted to participate received the EQ-5D and questions about age ( $<60, \geq 60$ years of age), sex $(M / F)$, diagnosis (primary $O A$, secondary $O A)$, Charnley class ( $A$ and $B$, or $C$ ), education (low, middle / high), cohabitation (yes, no), type of incision (lateral, posterior incision), and choice of implant fixation (cemented; or uncemented). The patients filled in these tasks themselves, and the nurse transferred the answers to an Excel file. Each patient was called for a follow up after 1 year.

In Sweden the patients visited the outpatient clinic 1-4 weeks before the operation, in order to get prepared for surgery. Basic demographic variables, details of the surgical procedure and implants used, details of any subsequent surgical procedure to the hip, and PROMs data were routinely registered and reported to the Swedish Joint Arthroplasty Register (SJAR). Each included individual was identified in all the registers through the unique personal identity number. SJAR aims to register all hip arthroplasties in Sweden, covering all hospitals, both public and private, with a completeness of approximately $97 \%$. As part of a national program for measuring patient-reported outcomes that is run by the Swedish Joint Arthroplasty Register, at the preoperative visit and 1 year postoperatively, all patients were asked to complete a patient-reported outcome measures (PROMs) questionnaire.

\section{The questionnaire}

In Bosnia and Herzegovina, an EQ5D form translated to the Bosnian language was used. Before the operation the patients visited an orthopaedic surgeon, in most cases the one who should perform the operation, an anaesthesiologist, a physiotherapist, and a nurse. At this visit patients were examined and given information about the type of anaesthesia and surgery, expected outcomes, the risk of complications, and rehabilitation after surgery. Each included patient was identified through the unique personal identity number. Data collection 1 year after operation was done at a routine follow up at the 2 hospitals. All data collection in Bosnia and Herzegovina was in paper form.

In Sweden, The PROM protocol comprised the HRQoL measure EQ-5D [17, 18, 21, 22], a VAS for pain, a Charnley classification survey $(A+B, C)[17,18,23]$, and a VAS addressing satisfaction after surgery [24]. Patients were contacted preoperatively in the clinic and 1 year postoperatively to complete the surveys. The questionnaire has been adapted to an internet-based touchscreen application for preoperative use in hospital clinics and is also optionally web-based. We used the 3 levels form that define each dimension as no problems, some or moderate problems, or extreme problems. The British tariff was used to score the EQ-5D index in this population. The inclusion criteria were provision of written informed consent to participate, immigrants from Europe excluding the Nordic countries living in Sweden, and completion of a preoperative standard-of-care PROMs questionnaire. We excluded patients with malignancy, patients scheduled for 1- 
stage bilateral THAs, patients with reoperations during the study period, and the 1st hip in patients who received their 2nd THA. In Sweden data were collected during build-up of the PROM programme which means that all operating units did not participate during the total period of data collection. In Bosnia and Herzegovina, the number of patients who declined participation is not known and all potential participants were not asked for logistical reasons. Ethical approval was obtained for both the parts of this study (see below).

\section{Measures}

The data collected for patients in Bosnia and Herzegovina were age, sex, education level, civil status, country of birth, family type, Charnley class, type of fixation and incision. Information about the type of hip disease (i.e. diagnosis) was obtained from the medical records. For Swedish patients (born in Europe outside the Nordic countries) these data were extracted from SJAR or obtained from Statistics Sweden by crossmatching with SJAR. Information about educational level (Low and Middle/High), and cohabitation (Yes/No) was provided by Statistics, Sweden. The simplified classification of educational was primarily based on classes according to the International Standard Classification of Education (ISCED) as designed by UNESCO (http://www.unesco.org).

The PROM form included are the 5 EQ5D questions, EQ-VAS, Pain-VAS, self-rated Charnley class and at 1 year Satisfaction-VAS. The EQ-VAS for general health ranges from 0 (worst imaginable health state) to 100 (best imaginable health state). The pain VAS ranges from 0 (no pain) to 100 (unbearable pain). At follow-up, a VAS for satisfaction with the outcome of the THR is used, where 0 represents complete satisfaction and 100 maximum dissatisfaction. To determine patient-reported comorbidity status, each patient completed the Charnley classification survey. During recent years, the PROM program in Sweden has had a response rate of $86 \%$ preoperatively and $90 \%$ one year postoperatively [2]. Data for patients from Bosnia and Herzegovina were collected between January 2016 to December 2018 and from patients operated in Sweden between 2002 and 2007. 86 of the patients operated in Tuzla, and 200 patients in Banjaluka completed their forms at both occasions.

\section{Statistical analysis}

To determine whether any of the 5 subcategories in the EQ-5D form (mobility, self-care, usual activities, pain/discomfort, anxiety/depression) could discriminate between patients living in Sweden but born in Europe outside the Nordic countries and patients living in Bosnia and Herzegovina, the answers were dichotomized into either no problems or moderate/severe problems for each of the 5 subcategories. Any differences between the 2 groups were tested using a non-parametric test (Chi-square, Fischer exact test). To evaluate any influence of covariates, we performed binary logistic regression analyses with use of the outcomes no problems/moderate or severe problems for each of 5 EQ-dimensions (mobility, self-care, usual activities, pain/discomfort, and anxiety/depression). The covariates included in the model were age $(<60, \geq$ 60 years of age), sex (M/F), diagnosis (primary OA, secondary $O A$ ), Charnley class ( $A$ and $B$, or $C$ ), education (low, middle / high), cohabitation (yes, no), type of incision (lateral, posterior incision), and choice of implant fixation (cemented; or uncemented). The item preoperative pain was not studied using regression analysis because at that time point almost all patients reported moderate/ severe problems for pain/discomfort. At the 1-year follow-up and for each of the dimensions studied (mobility, self-care, usual activities, 
pain/discomfort, anxiety/depression), the preoperative value for this dimension was also entered. VAS pain, VAS satisfaction, and EQ-VAS were analysed using Student's t-test, chi-square, linear and logistic regression. The deviation from normal distribution was judged to be within acceptable limits. The level of significance was set at $\mathrm{p}<0.05$. We used SPSS versions 25.0.

\section{Results}

\section{Demographics}

Out of the 729 patients 280 (38\%) were living in Bosnia and Herzegovina. There were 93 males (33\%) and 187 females (67\%) with a median age of 62 (26-89) years (Table 1). In the group living in Sweden there were 173 males (38\%) and 276 females (62\%) and the median age was 71 (28-93) years. Most patients living in Bosnia and Herzegovina had primary osteoarthritis $(227,81 \%)$, while secondary osteoarthritis was more common in the Swedish immigrant group $(414,3 \%)$. Cemented fixation of the implant was the most commonly used in the group of patients living in Sweden $(405,90 \%)$, whereas all patients in the other group were operated with an uncemented implant. Charnley class $\mathrm{C}$ was more frequent in the Swedish group (Sweden/Bosnia Herzegovina: $51 \% / 20 \%$ ) as was a status of living alone $(46 \% / 11 \%$ ) and low educational level $(44 \% / 22 \%)$. 
Table 1

Patient data

\begin{tabular}{|c|c|c|}
\hline Variables & Living in Sweden, $\mathrm{n}(\%)$ & Living in Bosnia and Herzegovina, $n(\%)$ \\
\hline \multicolumn{3}{|l|}{ Sex } \\
\hline Male & $173(38)$ & $93(33)$ \\
\hline Female & $276(62)$ & $187(67)$ \\
\hline \multicolumn{3}{|c|}{ Age, mean $(95 \% \mathrm{Cl})$} \\
\hline$<60$ years & $81(18)$ & $124(44)$ \\
\hline$\geq 60$ years & $368(82)$ & $156(56)$ \\
\hline Median age & $71(28-93)$ & $62(26-89)$ \\
\hline \multicolumn{3}{|l|}{ Diagnosis } \\
\hline Primary $O A$ & $35(7)$ & $227(81)$ \\
\hline Secondary OA & $414(93)$ & $53(19)$ \\
\hline \multicolumn{3}{|l|}{ Chamley class } \\
\hline$A+B$ & $224(49)$ & $224(80)$ \\
\hline C & $225(51)$ & $56(20)$ \\
\hline \multicolumn{3}{|l|}{ Cohabiting } \\
\hline Yes & $241(54)$ & $251(89)$ \\
\hline No & $208(46)$ & $29(11)$ \\
\hline \multicolumn{3}{|c|}{ Education (ISCED 97) } \\
\hline Low & $200(44)$ & $63(22)$ \\
\hline Middle / High & $249(56)$ & $218(78)$ \\
\hline \multicolumn{3}{|l|}{ Type of fixation } \\
\hline Cemented & $405(90)$ & $0(0)$ \\
\hline Uncemented & $44(10)$ & $280(100)$ \\
\hline \multicolumn{3}{|c|}{ Surgical Incision } \\
\hline Lateral & $203(45)$ & $71(25)$ \\
\hline Posterior & 246 (55) & 209 (75) \\
\hline
\end{tabular}

\section{Preoperative evaluation}


Preoperatively, a significantly higher share of patients born and living in Bosnia and Herzegovina reported moderate to severe problems with self-care and usual activities (Table $2, \mathrm{p}<0.0005)$. This was also mirrored in both the unadjusted and adjusted logistic regression analyses (Table 3). Preoperatively, patients living in Sweden reported higher EQ-VAS than those born in Bosnia and Herzegovina (53 vs. $42 ; p<0.0005$ ), but this difference did not reach statistical significance in the adjusted regression analysis (Table 4). The pain according to VAS was reported lower in the group of patients living in Bosnia and Herzegovina (41 vs. 62; $\mathrm{p}<0.0005$ ) (Table 2). 
Table 2

Preoperative and 1year postoperative data of the Pain/Satisfaction and EQVAS, and EQ5D questions.

Preoperatively

\section{Mean or $95 \% \mathrm{Cl}$ of}

numbers mean or

percentages p-value 1 year

Mean or $95 \% \mathrm{Cl}$ of

numbers mean or $p$

value $^{7}$

$\begin{array}{llll}\begin{array}{l}\text { Mean or } \\ \text { numbers }\end{array} & \begin{array}{l}95 \% \mathrm{Cl} \text { of } \\ \text { mean or } \\ \text { percentages }\end{array} & \begin{array}{l}\text { Mean or } \\ \text { numbers }\end{array} & \begin{array}{l}95 \% \mathrm{Cl} \text { of } \\ \text { mean or }\end{array} \\ & & \text { percentages }\end{array}$

\section{Pain VAS}

Living in Sweden

62

61-64

$<0.0005$

19

40-43

15

$17-21$

$<0.0005$

Living in Bosnia and Herzegovina

41

\section{Satisfaction VAS}

Living in Sweden

Living in Bosnia and Herzegovina

20

13

$18-22$

12-13

\section{EQVAS}

Living in Sweden

53

51-55

$<0.0005 \quad 71$

69-73

$<0.0005$

Living in Bosnia

42

40-44

76

74-78

\section{EQ5D questions}

no

problems/moderate

or severe problems

Mobility

Living in Sweden

$19 / 430$

$4 / 96$

0.5

242/207

$54 / 46$

$<0.0005$

Living in Bosnia

and Herzegovina

$11 / 269 \quad 4 / 96$

$254 / 26$

$91 / 9$

Self-care

Living in Sweden

$309 / 140$

69/31

$<0.0005$

$378 / 71$

$84 / 16$

0.8

Living in Bosnia

$85 / 195 \quad 30 / 70$

$234 / 46$

$84 / 16$

and Herzegovina

Usual activities

Living in Sweden

$162 / 287 \quad 36 / 64$

$<0.0005$

$296 / 153$

$66 / 34$

$<0.0005$

Living in Bosnia and Herzegovina

$40 / 240 \quad 14 / 86$

$245 / 35$

$87.5 / 12.5$

${ }^{1} \mathrm{t}$-test or chi-square 


\begin{tabular}{|lllllll|}
\hline & Preoperatively & p-value & 1 year & & $\begin{array}{c}\text { p- } \\
\text { value }^{\mathbf{1}}\end{array}$ \\
\hline Pain/discomfort & & & & & & \\
\hline Living in Sweden & $5 / 444$ & $1 / 99$ & 0.05 & $167 / 282$ & $37 / 63$ & $<0.0005$ \\
\hline $\begin{array}{l}\text { Living in Bosnia } \\
\text { and Herzegovina }\end{array}$ & $9 / 271$ & $3 / 97$ & & $238 / 42$ & $85 / 15$ & \\
\hline $\begin{array}{l}\text { Anxiety/Depression } \\
\text { Living in Sweden }\end{array}$ & $195 / 254$ & $43 / 57$ & 0.7 & $293 / 156$ & $65 / 35$ & 0.001 \\
\hline $\begin{array}{l}\text { Living in Bosnia } \\
\text { and Herzegovina }\end{array}$ & $126 / 154$ & $45 / 55$ & & $216 / 65$ & $77 / 23$ & \\
\hline \begin{tabular}{l} 
7t-test or chi-square \\
\hline
\end{tabular} & & & & & & \\
\hline
\end{tabular}


Table 3

Results of logistic regression analyses for the 5 EQ5D questions. (Values above 1 indicate that patients living in Sweden more frequently report moderate or severe problems.)

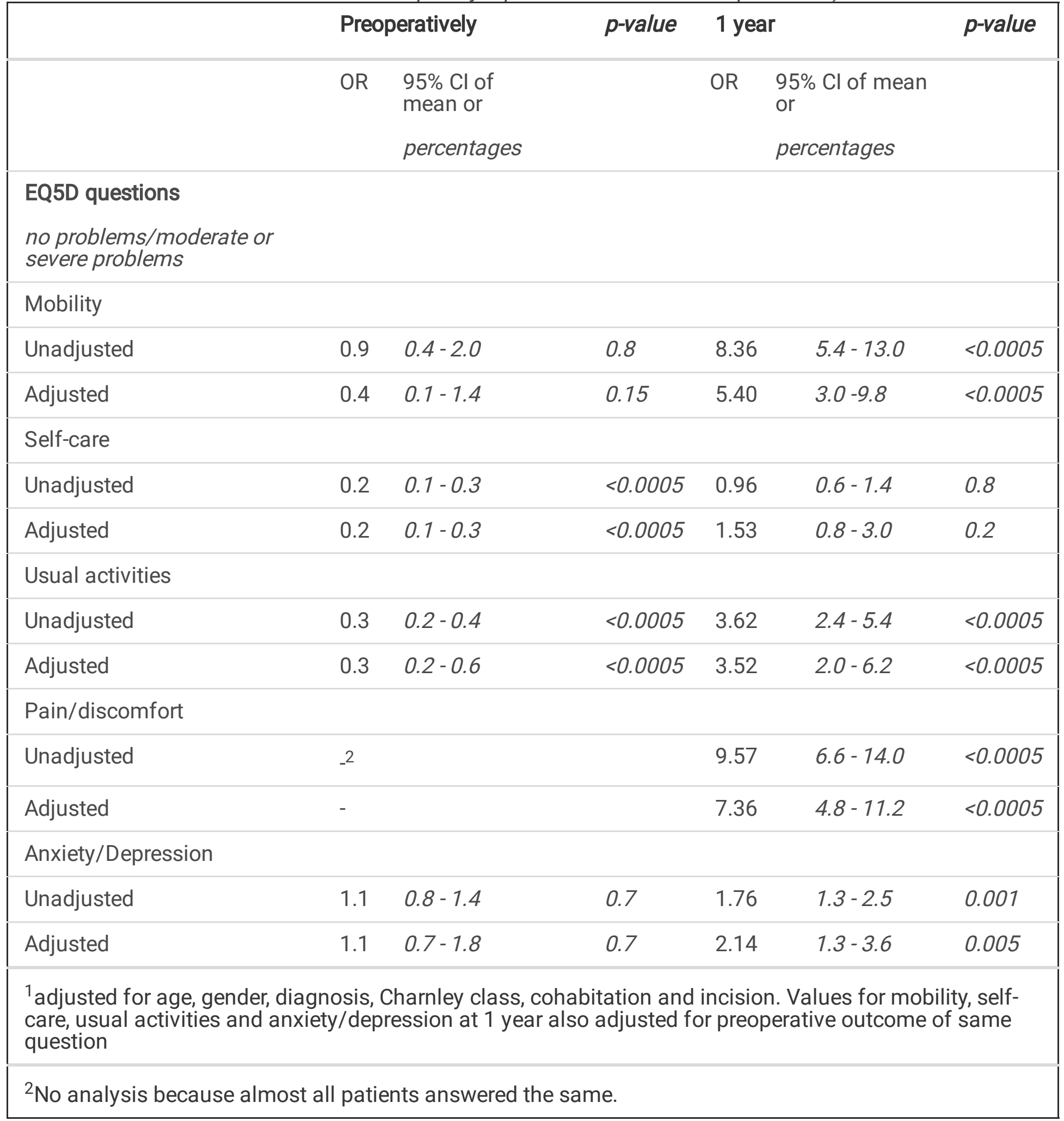


Table 4

Analyses of pain- Satisfaction and EQVAS in general linear models.

\begin{tabular}{|c|c|c|c|c|c|c|}
\hline & \multicolumn{2}{|c|}{ Preoperatively } & \multirow[t]{2}{*}{ p-value } & \multicolumn{2}{|c|}{1 year } & \multirow[t]{2}{*}{ p-value } \\
\hline & $\mathrm{B}$ & $95 \% \mathrm{Cl}$ & & B & $95 \% \mathrm{Cl}$ & \\
\hline \multicolumn{7}{|l|}{ Pain VAS } \\
\hline Unadjusted & 20.7 & $18.1-23.3$ & $<0.0005$ & 3.2 & $0.6-5.9$ & 0.18 \\
\hline Adjusted $^{1}$ & 15.74 & $12.0-19.5$ & $<0.0005$ & 2.4 & $-1.7-6.5$ & 0.25 \\
\hline \multicolumn{7}{|c|}{ Satisfaction VAS } \\
\hline Unadjusted & - & & & 7.3 & $4.6-10.0$ & $<0.0005$ \\
\hline Adjusted $^{1}$ & - & & & 8.7 & $4.5-12.9$ & $<0.0005$ \\
\hline \multicolumn{7}{|l|}{ EQVAS } \\
\hline Unadjusted & 10.9 & $7.8-13.9$ & $<0.0005$ & -5.2 & $-8.2--2.3$ & 0.001 \\
\hline Adjusted ${ }^{1}$ & 2.0 & $-2.8-6.7$ & 0.41 & -5.2 & $-9.7-0.7$ & 0.25 \\
\hline
\end{tabular}

\section{Postoperative evaluation}

A higher share of patients living in Bosnia and Herzegovina reported more benefit 1 year after the operation in all dimension except from self-care as reflected in the basic chi-square test and the unadjusted regression analyses. After adjustment for confounding the results only changed marginally. At 1 year postoperatively, patients living in Sweden reported lower EQ-VAS than those living in Bosnia and Herzegovina (71 vs. 76: $\mathrm{p}<0.0005)$. The pain according to VAS was reported lower in the group of patients living in Bosnia and Herzegovina (15 vs. $19 ; p<0.0005$ ). After adjustment for covariates, the patients born and living in Bosnia and Herzegovina, turned out to be more satisfied than those living in Sweden (13 vs 20; $p<0.0005)$ (Table 2), whereas the observed differences in pain VAS and EQ-VAS did not reach statistical significance.

\section{Discussion}

Overall there are very few studies comparing outcomes between patient groups with similar ethnicity living in their country of birth or in a foreign country to which they have emigrated. A few studies have focused on PROMs reported from various immigrant groups within a country using the native population as reference. In an earlier study we examined immigrants divided into three different groups depending on region of birth and compared the patient reported outcomes 1 year after total hip arthroplasty with those reported by patients born in Sweden. All 3 immigrant groups reported more problems in the dimension self-care and usual activities and a tendency to a higher level of anxiety/depression the longer the distance to their country of birth. Immigrants born in Europe outside the Nordic countries had a higher risk of reoperation than had 
patients born outside Sweden. They also more frequently reported that they were poorly informed in comparison with the native patient group $[14,17,18]$.

Our study confirms previous findings that immigrants are at increased risk of inferior results also after a standard procedure such as total hip arthroplasty. There are numerous possible reasons such as history of living in areas of conflicts and a traumatic escape from such areas, loss of relatives and friends, loss of previous social status and for some deteriorating economy. Despite that we do not know the specific home country for the immigrants here evaluated (born in Europe outside the Nordic countries) our observations support the hypothesis that the inferior results in the immigrant group most probably can be related to their immigrant status and to a lesser extent methodological errors even if such errors cannot be ruled out.

Oldsberg et al (2019) [25]. studied differences in PRO data before and after THA between Swedish counties. The variations of follow up data could not be explained by differences in preoperative data after adjustment for different patient demographics including socioeconomic variations. They thought that local differences in outcome could be due to differences in indications for surgery and lack of standardized care. This theory is partly supported by Judge et al. (2019) [26], who noted that the incidence of THA in different regions of England was influenced by socio-demographic factors. To which extent indications for surgery varied between the 2 groups of patients studied by us is not known, but such a variation could be a source of bias.

The differences in outcome found in the present study may be explained by a number of reasons. First, the EQ-5D as questionnaire, is a generic scale that has previously been empirically tested in many occasions, in different languages and in different cultural groups and has a high validity and reliability to measure healthrelated quality of life, which is a strength [27]. It also opens up for comparisons between study populations, which creates an understanding and context around the results. At the same time, it is challenging to create semantically, conceptually and technically equivalent dimensions in different language versions as the constructions that are translated may not fully fit into the new linguistic and cultural context [28]. As far as we are aware EQ-5D form has not previously been tested in a refugee population, which could be a weakness of our study and affect the validity of the results [29]. Previous studies have also shown some inconsistencies when using EQ-5D cross-culturally. It should be mentioned that the results from our study are time- and context-bound and at best only apply to the current study population. If these forms are transferable to other refugee groups with a different national background remains unknown [30]. In our study patients living in Bosnia and Herzegovina received EQ-5D forms translated into Bosnian language. If wanted, they could receive help from a nurse to fill in the form, while those living in Sweden received the form using a validated and well-establish Swedish translation. Before the operation patients in Sweden could use an electronic form and could receive assistance from a nurse. At 1 year postoperatively, the forms were sent to the patients in Sweden by post, while patients living in Bosnia and Herzegovina filled in the form at the outpatient clinic. Patients in both countries could have received help from relatives, probably more so in Sweden than in Bosnia-Herzegovina where a dedicated nurse always was present. To what extent this actually occurred is unknown to us.

Cultural differences, like participation of the family in the care of patients and differences in health-care system between Sweden and southern Europe are other possible confounders. A previous report pointed out that in southern Europe there is often a higher involvement of family in care than in the northern countries 
due to low female employment and limited public responsibility [31], which applies not only to Bosnia and Herzegovina but also Greece and Spain [32,33]. Family with all their aspects, often assume the role of the informal caregiver, a role that is imposed by the cultural norms and promoted by the society [34]. Hospitals and rooms where patients stay in Bosnia and Herzegovina and Sweden do not differ in size, but the immigrant patient may in a Swedish hospital experience more or less problems related to cultural identity.

Language barriers and communication problems can negatively affect the outcome of a surgical procedure such as a THA $[14,16]$. In the present study, patients operated in Bosnia and Herzegovina communicated in their mother tongue, were most often operated on in the city where they were born, had regular support and family visits, and had the same ethnic and cultural background as their caregivers. For patients operated on in Sweden, the situation was more or less opposite. Several studies have found that the reported quality of life according to HRQoL instruments and self-perceived health status increases with improved socioeconomic status and education [35-37]. In our study, income and education of patients from the group living in Bosnia and Herzegovina and those living in Sweden were not analyzed. One reason is the different cost level in the two countries. The welfare reimbursement in Sweden is higher than the average salary of an employee in Bosnia and Herzegovina. Neither is it easy to estimate the educational level in patients living in Bosnia Herzegovina. 78 percent in this population claimed a high level of education, but this share should be viewed in the light of locally easily buyable diplomas or certificates of educational degrees on the black market.

As mentioned above our study has limitations. When this study was planned, we aimed to compare patients born and operated on in Bosnia and Herzegovina with patients born in these countries but operated in Sweden due to emigration. If necessary, and due to insufficient sample size patients from neighbor countries could become included. Unfortunately, detailed information about country of birth was not made available to us. Therefore, the closest we could get was patients born in Europe outside the Nordic countries. Another limitation could be use of the 3 level EQ-5D questionnaire since the 5-level version probably would have resulted in more nuanced and representative answers in the populations studied [38].

In conclusion, we found that immigrants in Sweden from Europe outside the Nordic countries report less problems with health care and usual activities before operation with THA than those operated on in Bosnia and Herzegovina. One year after the THA, patients operated in their native country did however, report a higher degree of improvement according to 4 of the 5 EQ5D dimensions and a higher degree of satisfaction than did the immigrant group. The reason for this is not known. A more comfortable and socially safer home environment is a plausible explanation, but other factors such as the health care system itself including patient payment for THA in Bosnia and Herzegovina and methodological errors related to the questionnaires used cannot be ruled out. Since the number of immigrants are increasing in most European countries further studies are eligible to evaluate and optimize the health care situation for these patients.

\section{Abbreviations}

THA - Total Hip Arthroplasty

SJAR - Swedish Joint Arthroplasty Register

Page 14/18 
EQ5D - Equality of Life in 5 dimensions

VAS - Visual Analog Scale

PROM - Patient Reported Outcome Measurement

HRQoL - Health Related Quality of Life

\section{Declarations}

\section{Acknowledgments}

The authors would like to thank all health care professionals from Sweden and Bosnia and Herzegovina who contributed data of the study.

\section{Funding}

No external funding was received

\section{Data Availability}

The datasets generated and analyzed during the current study are not publicly available due to ethical restrictions in Sweden as regards registry data but are available from the corresponding author on reasonable request.

\section{Author's contribution}

FK and JK study design, SM, SS, FK, JK data collection, FK, JK, SC and MF database preparation, FK and JK data analysis, manuscript drafting and editing. All the authors have read and approved the final manuscript.

\section{Author's information}

Not relevant

\section{Competing interest}

The authors declare that they have no competing interest

\section{Ethics approval and consent to participate}


The study was approved by the Regional Ethical Review Board in Gothenburg, Sweden (Dnr.: 271-14), Regional Ethical Review Board in Banja Luka, Bosnia and Herzegovina (Dnr.: 116-16-8017/2016), and the Regional Ethical Review Board in Tuzla, Bosnia and Herzegovina (Dnr.: 02-09/2-4/2016). In according to the Swedish Patient Data Act (2008:355) patients receive information about being registered and have full right to opt-out.

\section{Author details}

${ }^{1}$ Department of Anesthesiology, Institute of Clinical Sciences, Sahlgrenska Academy, University of Gothenburg, Gothenburg, Sweden

${ }^{2}$ Department of Orthopaedics, Institute of Clinical Sciences, Sahlgrenska Academy, University of Gothenburg, Gothenburg, Sweden.

${ }^{3}$ School of Medicine, University of Banjaluka, Banjaluka, Bosnia and Herzegovina.

${ }^{4}$ Clinic for Orthopaedics and Traumatology, University Clinical Center Tuzla, Bosnia and Herzegovina

${ }^{5}$ Swedish Joint Arthroplasty Register, S-413 45 Gothenburg, Sweden.

\section{References}

1. Bourne RB, Chesworth BM, Davis AM, Mahomed NN, Charron KD. Patient satisfaction after total knee arthroplasty: who is satisfied and who is not? Clin Orthop. Relat Res 2010; 468 (1):57-63.

2. Kärrholm J, Mohaddes M, Odin D, Vinblad J, Rogmark C, Rolfson O. Swedish Hip Arthroplasty Register. Annual report 2017 (in Swedish); 2018.

3. Halawi MJ, Jongbloed W, Baron S, Savoy L, Williams VJ, Cote MP. <background-color:\#CCCCFF; uverticalalign:super;>Patient Dissatisfaction After Primary Total Joint Arthroplasty: The Patient Perspective</background-color:\#CCCCFF;uvertical-align:super;><uvertical-align:super;>.</uverticalalign:super;><uvertical-align:super;></uvertical-align:super;>J Arthroplasty. 2019; 34 (6): 1093-96.

4. Wylde V, Blom AW, Whitehouse SL, Taylor AH, Pattison GT, Bannister GC. Patient-reported outcomes after total hip and knee arthroplasty: comparison of midterm results. J Arthroplasty. 2009; 24 (2): 210-6.

5. Choi YJ, Ra HJ. Patient Satisfaction after Total Knee Arthroplasty. Knee Surg Relat Res. 2016; 28 (1):115.

6. Van Onsem S, Van Der Straeten C, 'Deprez NAP, Van Damme' JV. A New Prediction Model for Patient Satisfaction After Total Knee Arthroplasty. J Arthroplasty. 2016; 31 (12): 2660-7.

7. Skinner J, Weinstein JN, Sporer SM, Wennberg JE. Racial, ethnic, and geographic disparities in rates of knee arthroplasty among Medicare patients. N Engl J Med 2003; 349: 1350-9.

8. Klopfenstein CE, Forster A, Van Gessel E. Anesthetic assesstment in an outpatient consultation clinic reduces preoperative anxiety. Can J Anaesth 2000; 47 (6): 511-5.

9. Hughes S. The effects of giving patients pre-operative information. Nurs Stand 2002; 16 (28): 33-7. 
10. Lee A, Chui PT, Gin T. Educating patients about anaesthesia: a systematic review of randomized controlled trials of media-based interventions. Anesth Analg 2003; 96 (5): 1424-31.

11. Green CR, Baker TA, Smith EM, Sato Y. The effect of race in older adults presenting for chronic pain management: a comparative study of black and white Americans. J. Pain 2003; 4 (2): 82-90.

12. Hawker GA. Who, when and why total joint replacement surgery? The patient's perspective. Curr Opin Rheumatol 2006; 18 (5): 526-30.

13. Francis ML, Scaife SL, Zahnd WE, Cook EF, Schneeweiss S. Joint replacement surgeries among medicare beneficiaries in rural compared with urban areas. Arthritis Rheum 2009; 60 (12): 3554-62.

14. Krupic F, Eisler T, Eliasson T, Garellick G, Gordon M, Kärrholm J. No influence of immigrant background on the outcome of total hip arthroplasty. 140,299 patients born in Sweden and 11,539 immigrants in the Swedish Hip Arthroplasty Register. Acta Orthop. 2013; 84 (1): 18-24.

15. SCB. Statistisk årsbok för Sverige (Statistical Yearbook for Sweden), 2019. Elanders Novum AB, Stockholm.

16. Krupic F, Määttä S, Garellick G, Lyckhage ED, Kärrholm J. Preoperative information provided to Swedish and immigrant patients before total hip replacement. Med Arch. 2012; 66 (6): 399-404.

17. Krupic F, Garellick G, Gordon M, Kärrholm J. Different patient-reported outcomes in immigrants and patients born in Sweden: 18,791 patients with 1 year follow-up in the Swedish Hip Arthroplasty Registry. Acta Orthop. 2014; 85 (3): 221-8.

18. Krupic F, Rolfson O, Nemes S, Kärrholm J. Poor patient-reported outcome after hip replacement, related to poor perception of perioperative information, commoner in immigrants than in non-immigrants. Acta Orthop. 2016; 87 (3): 218-24.

19. Cainzos-Achirica M, Fedeli U, Sattar N, Agyemang C, Jenum AK, McEvoy JW, et al. <backgroundcolor:\#CCCCFF;uvertical-align:super;>Epidemiology, risk factors, and opportunities for prevention of cardiovascular disease in individuals of South Asian ethnicity living in Europe</backgroundcolor:\#CCCCFF;uvertical-align:super;><uvertical-align:super;>.</uvertical-align:super;><uverticalalign:super;></uvertical-align:super;>Atherosclerosis. 2019; 286:105-113.

20. Demeke T, Osmancevic A, Gillstedt M, Krogstad AL, Angesjö E, Sinclair H, et al. <backgroundcolor:\#CCCCFF;uvertical-align:super;>Comorbidity and health-related quality of life in Somali women living in Sweden</background-color:\#CCCCFF;uvertical-align:super;><uvertical-align:super;>.</uverticalalign:super;> Scand J Prim Health Care. 2019; 37 (2):174-81.

21. EuroQol group, EuroQol-a new facility for the measurement of health related quality of life. Health Policy 1990; 16 (3): 199-208.

22. Nilsdotter AK, Petersson IF, Roos EM, Lohmander LS. Predictors of patient relevant outcome after total hip replacement for osteoarthritis: a prospective study. Ann Rheum Dis 2003, 62 (10): 923-30.

23. Charnley J. Low friction arthroplasty of the hip:theory and practice. Springer-Varlag, Berlin, 1979.

24. Carr-Hill RA. Health related quality of life measurement-Euro style. Health Policy 1992; 20 (3): $321-8$.

25. Oldsberg L, Garellick G, Osika Friberg I, Samulowitz A, Rolfson O, Nemes S. Geographical variations in patient-reported outcomes after total hip arthroplasty between 2008 - 2012. BMC Health Serv Res. 2019;19 (1): 343. 
26. Judge A, Welton NJ, Sandhu J, Ben-Shlomo Y. Geographical variation in the provision of elective primary hip and knee replacement: the role of socio-demographic, hospital and distance variables. J Public Health (Oxf). 2009; 31 (3): 413-22.

27. Rabin R, de Charro F. EQ-5D: a measure of health status from the EuroQol Group. Annals of Medicine, 2001; 33 (5): 337-343.

28. Crea T, Calvo R, Loughry M. Refugee health and wellbeing: Differences between urban and cam-based environments in sub-Saharan Africa. Journal of Refugee Studies, 2015; 28 (3): 319-330.

29. Hollified M, Warner T, Lian N, Krakow B, Jenkins J, Kesler J, et al. Measuring trauma and health status in refugees. A critical review. JAMA, 2002; 288 (5): 611-621.

30. Leung B, Luo N, So L, Quan H. Comparing three measures of health status (Percieved health with likerttype scale, EQ-5D, and number of chronic conditions) in Chinese and white Canadians. Medical Care, 2007; 45 (7): 610-17.

31. Lamura G, Mnich E, Nolan M, Wojszel B, Krevers B, Mestheneos L, et al. Family carers' experiences using supportservices in Europe: empirical evidence from the EURO-FAMCARE study. Gerontologist 2008;48 (6): 752-71.

32. Zabalegui A, Bover A, Rodriguez E, Cabrera E, Diaz M, Gallart A, et al. Informal caregiving: perceived needs. Nurs Sci Q 2008; 21 (2): 166-72.

33. Sapountzi-Krepia D, Raftopoulos V, Psychogiou M, Sakellari E, Toris A, Vrettos A, et al. Dimensions of informal care in Greece: the family's contribution to the care of patients hospitalized in an oncology hospital. J Clin Nurs 2008; 17 (10): 1287-94.

34. Papastavrou E, Charalambous A, Tsangari $\mathrm{H}$, Karayiannis $\mathrm{G}$. The burdensome and depressive experience of caring: what cancer, schizophrenia, and Alzheimer's disease caregivers have in common. Cancer Nurs 2012; 35 (3): 187-94.

35. Von Rueden U, Gosch A, Rajmil L, Bisegger C, Ravens-Sieberer U. Socioeconomic determinants of health related quality of life in childhood and adolescence: results from a European study $\mathrm{J}$ Epidemiol Community Health. 2006; 60 (2): 130-5.

36. Serrano-Aguilar P, Ramallo-Farina Y, Trujillo Mariın MDM, Munoz-Navarro S R, Perestelo-Perez L, CuevasCastresana CDL. "The relationship among mental health status (GHQ-12), health related quality of life (EQ-5D) and health-state utilities in a general population," Epidemiologia e Psichiatria Sociale, 2009; 18 : 229-39.

37. Mielck A, Reitmeir P, Vogelmann M, Leidl R. "Impact of educational level on health-related quality of life (HRQL): results from Germany based on the EuroQol 5D (EQ-5D)," European Journal of Public Health,2012; 23 (1): 45-9.

38. Eneqvist T, Nemes S, Kärrholm J, Burström K, Rolfson O. How do EQ-5D-3L and EQ-5D-5L compare in a Swedish total hip replacement population? Acta Orthop. 2020; 91 (3): 272-78. 